\title{
A rare case of sacral parasitic rachipagus
}

\author{
Authors: J. B. Bikoroti1, ${ }^{1}$; A. Jahnn ${ }^{1}$; S. Muneza ${ }^{1}$; M. Nyundo ${ }^{1}$; J. K. Gashegu²; A. M. Buteera ${ }^{3}$ \\ Affiliations: ${ }^{1}$ University Teaching Hospital of Kigali, Rwanda; ${ }^{2}$ University of Rwanda; ${ }^{3}$ Rwanda \\ Military Hospital, Rwanda
}

\begin{abstract}
BACKGROUND: A sacral parasitic twin is a variant of conjoined twins in which one twin is incomplete.

CASE: A female newborn was delivered by cesarean section. Reported inconclusive obstetrical ultrasonography at the first trimester where the pregnancy was initially diagnosed dizygotic and in the second and third trimester was monozygotic. The neonate was born with a mass in the sacrococcygeal region, which was excised 24 days after birth. The mass contained the scalp, skull, cervical spine bone, and brain, which were confirmed as parasitic twins. The post-operative and follow up periods were uneventful.
\end{abstract}

CONCLUSION: Sacral parasitic rachipagus is a rare phenomenon; experienced antenatal ultrasonography may assist in the early diagnosis and excision is the treatment.

Keywords: Sacral, Parasitic twin, Rachipagus, Abnormal Gastrulation, Teratoma, Rwanda

\section{INTRODUCTION}

A Sacral parasitic twin is a variant of conjoined twins in which one twin is incomplete. A sacral parasitic twin is among presentations originating from one fertilized ovule, one placenta, and the same genetic sex [1]. Conjoint twins are rare embryologic developmental anomalies with an estimated prevalence of 1 in 50,000 to 1 in 100,000 births. Parasitic or heteropagus twins are used as synonymous with asymmetric twins. Heteropagus (parasitic) twin is a type of conjoined twinning in which a partially formed defective twin is attached to an otherwise normal twin. It is an extremely rare anomaly $[2,3]$.

The recognized nomenclature includes eight such sites: the chest (thoracopagus), umbilicus (omphalopagus), hip (ischiopagus), buttocks (pygopagus), spine (rachipagus), side (parapagus), cranium (craniopagus), and head (cephalopagus) $[4,5]$.

Case: A female neonate was born at Gihundwe district hospital, located in the western region of Rwanda, bordering The Democratic Republic of Congo (DRC).

This was the mother's second pregnancy, with her firstborn dying on day one of life from a febrile respiratory illness without physical abnormalities. The mother was aged 20 years, with prenatal visits done in DRC and Gihundwe hospital, Rwanda. No significant abnormalities were noted during antenatal clinical examinations and no parental consanguinity was reported. HIV status

\footnotetext{
*Corresponding author: Dr. Joël Bizimanasharale Bikoroti, Consultant General Surgeon, Department of Surgery, University Teaching Hospital of Kigali, Rwanda, Email: drbikorotijoel@gmail.com; Potential Conflicts of Interest (Col): All authors: no potential conflicts of interest disclosed; Funding: All authors: no funding was sought; Academic Integrity. All authors confirm that they have made substantial academic contributions to this manuscript as defined by the ICMJE; Ethics of human subject participation: The study was approved by the local Institutional Review Board. Informed consent was sought and gained where applicable; Originality: All authors: this manuscript is original has not been published elsewhere; Review: This manuscript was peer-reviewed by three reviewers in a double-blind review process; Type-editor: Batenhorst (USA)
}

Received: $30^{\text {th }}$ March 2021; Initial decision given: $13^{\text {th }}$ August 2021; Revised manuscript received: $13^{\text {th }}$ August 2021; Accepted: $10^{\text {th }}$ October 2021. Copyright: (C) The Author(s). This is an Open Access article distributed under the terms of the Creative Commons Attribution License (CC BY-NC-ND) (click here) which permits unrestricted use, distribution, and reproduction in any medium, provided the original work is properly cited. Publisher: Rwanda Biomedical Centre (RBC)/Rwanda Health Communication Center, P. O. Box 4586, Kigali. ISSN: 2079-097X (print); 2410-8626 (online) 
of the mother was reported negative. Prenatal Ultrasound was undertaken at 3 months, 5 months and 9 months, and noted twins, single, and single fetus respectively. No prenatal vitamins were used during the pregnancy.

He was born by Cesarean section with a total body weight of $3,020 \mathrm{~kg}$, with a sacrococcygeal mass noted after birth. On day two of life, the neonate presented with fever and, on the third day, convulsed and was referred to the University teaching hospital of Kigali. The neonate was admitted to the pediatric neonate unit.

Neonatal examination revealed a sacrococcygeal haired mass of $34 \mathrm{~cm}$ circumference, nodular, bony-hard feeling underneath the skin, not tender, mobile and vascularized. The mass was located at around $4 \mathrm{cms}$ above the permeable anus, a head-like mass with a tuft of hairs. Viewed at the anterior, which is the most posterior aspect, sacral mass was a face-like similar to a "cyclopia face" (Figure 1).

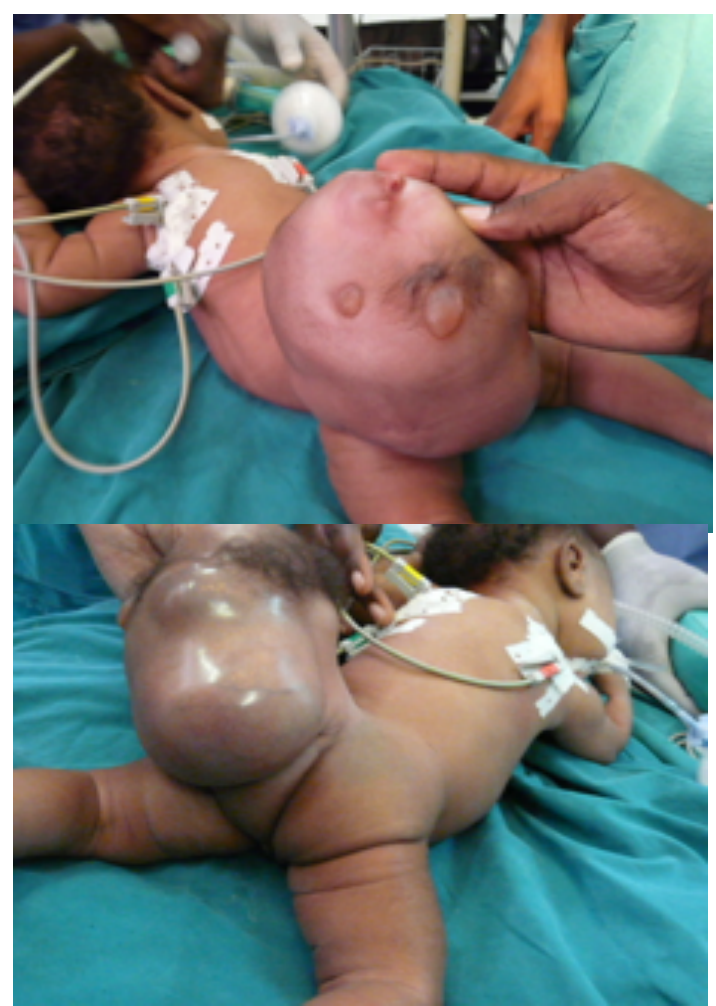

Figure 1: Pre-operative mass examination and evaluation

The neonate was put on Phenobarbital, 10\% Dextrose, Cefotaxime, Gentamicin and suppository paracetamol prior to definitive surgical diagnosis.
The working diagnosis was neonatal infection associated with teratoma or sacral neoplasia

Ultrasound scan showed a huge soft tissue mass adjacent to the sacral region posteriorly and containing multiple bone structures within the lower portion. However, the mass appeared to be separated from the patient by skin, joined via vertebral body bone-like structures. These findings led to a Teratoma as the most likely diagnosis to rule out Dermoid/ Epidermoid mass.

Spine radiography found skull-like and small cervical spine column bones within the parasite attached to the sacral area (Figure 2).

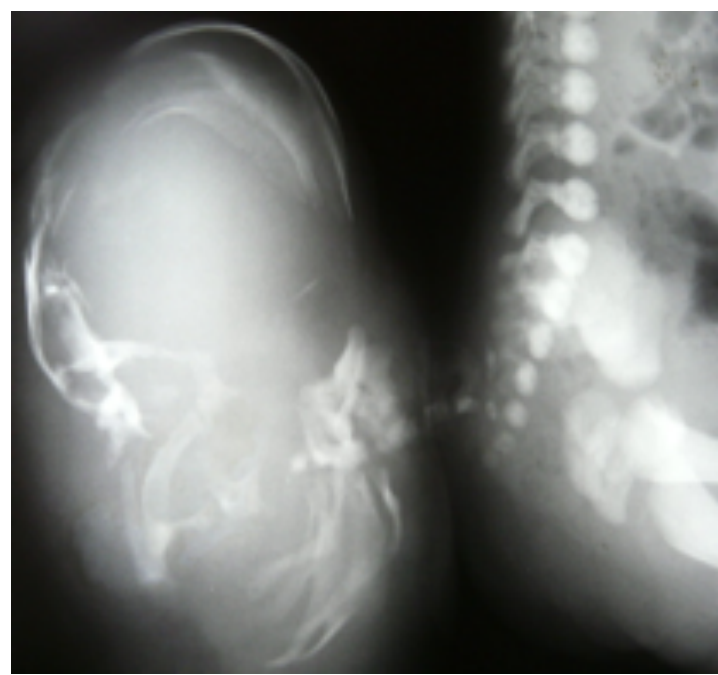

Figure 2: X-Ray findings of the parasitic twin

The sacral parasitic twin (Rachipagus) was diagnosed, and an excision of the parasitic twin from the healthy twin was planned.

Surgery was done on day-24-of-life and the excision of the parasite twin was successfully performed under general anesthesia. Perioperative findings were that of large bilaterally lateral vessels from the mass to the child which were ligated. No evidence of the spinal cord through the structured C-spine was found. Post-defect closure was undertaken and a dissection of the excised mass showed clear macroscopic brain tissue, soft skull and cervical bones. The post-operative period was uneventful and the child was discharged on day-32-of-life.

The Follow-up investigation showed an $\alpha$-fetoprotein of $203.90 \mathrm{kUI} / \mathrm{l}(<6.00 \mathrm{kUI} / \mathrm{l})$ from 07/06/2011 done at Biomnis (France). A decision to keep following up on the growth of the child 
was taken. Reviewed on $1^{\text {st }}$ June 2011 , the child presented with a well-healed surgical wound and in good general condition (Figure 3).

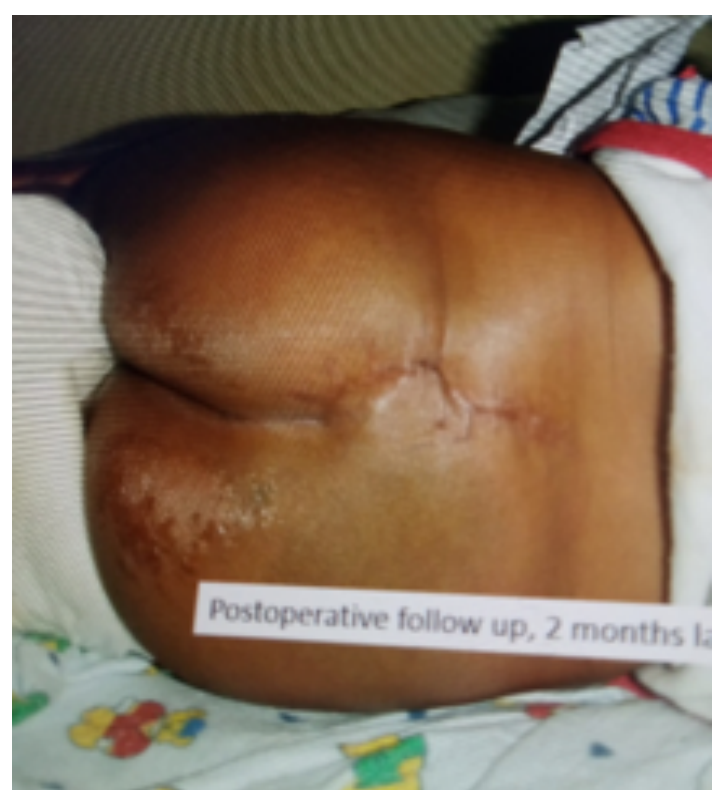

Figure 3: First postoperative follow-up with wound healing

Follow up at 3 years 6 months of age was planned on 18th August 2014 and the child had started school, was in nursery three and growing normally without any problem (Figure 4).

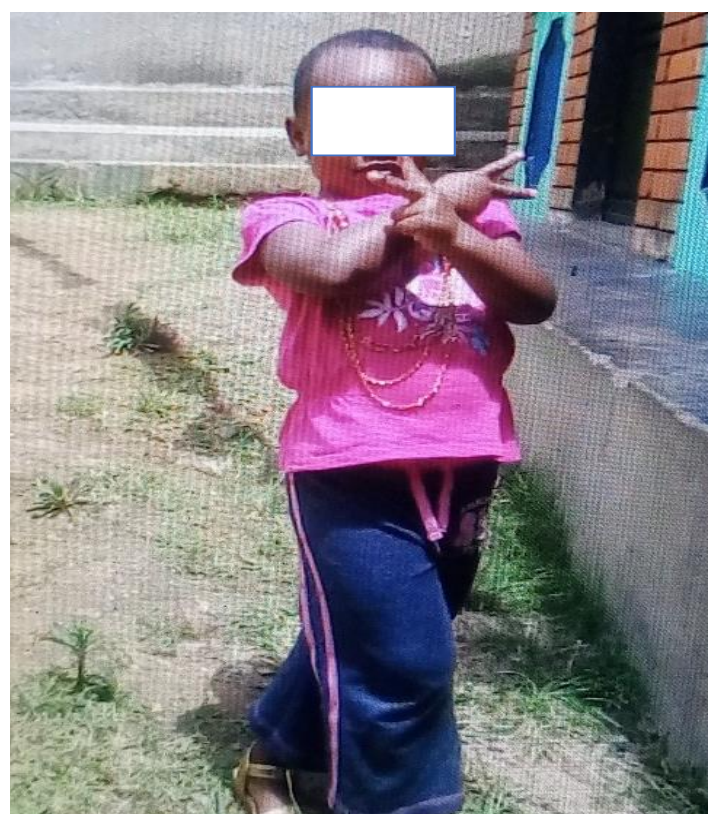

Figure 4: The second follow up review of the child at $\mathbf{3 . 6}$ years-old
An online acceptance to publish the case from parents was obtained ( $2^{\text {nd }}$ December 2020).

\section{DISCUSSION}

Conjoined twins are monozygotic, monoamniotic, and monochorionic. They are always of the same gender, with a 3:1 female preponderance. Their formation results either from a failure of separation of the embryonic plate between 15and 17-days gestation or from the secondary union of two separate embryonic discs at the dorsal neural tube or ventral yolk sac areas at 3 to 4 weeks gestation. Conjoined twins arise from the incomplete splitting of the blastocyst's inner cell mass or embryoblast while hatching at 7-8 days of gestation. Conjoined twins can also result from the duplication of the primitive node, the organizer of the gastrulation. In this case, the parasitic twin can be considered a more differentiated teratoma that has developed in a head-like mass. Its presentation and features suggested that a second rudimentary axis of the embryo has begun at the caudal aspect of the primitive streak after its regression during the $3 r d$ week of the pregnancy. While ending its regression, the primitive streak becomes the caudal eminence which is the primordial of the sacral spinal cord and lower limbs' derivate of the sacral somites and neural crest. The features of this parasitic twin were suggested to result from abnormal development of the caudal eminence. The natural history that follows a prenatal diagnosis of conjoined twins confirms that a large number of infants die either in utero (28\%) or immediately after birth (54\%); in fact, only around $20 \%$ survive $[5,6,7]$.

The risk of developing a parasitic twin is around one in 500,000 births. There have only been about 90 such recorded cases in the world [8]. A parasitic twin represents a rare developmental anomaly in which an asymmetrical, nonviable conjoined twin is attached to the host body at the time of birth [4].

The incidence of the various types of conjoined twinning is discussed. The spontaneous incidence is about 10 per million births. 40 to $60 \%$ of conjoined twins are stillborn, and $70 \%$ are female. Parasitic twins account for $10 \%$ of conjoined twins $[7,9]$. The estimated incidence of heteropagus twins is approximately 1 per 1 million live births $[5,10]$. 
Kamal Nain Rattan et al. reported a case of the sacral rachipagus parasite, which was vaginally delivered as a large irregular mass attached to the sacral region by a vascular pedicle, gross morphology of sacral parasite twin with rudimentary limb [2].

Chou SY et al. reported a female infant was born vaginally at 40 weeks' gestation to a healthy primipara. No important abnormalities were noted during prenatal examinations. The infant was fully developed in all external aspects except for a parasitic body conjoined with her sacrococcygeal region. Separated by operation 2 weeks after birth, the parasite contained lower limbs, adipose tissue, muscles, and a bowel sac. Over 4 years of observation, no abnormalities have been found since the operation [11].

Maria Okumura reported a $5 \mathrm{~cm}$ mass expelled during delivery of the trunk. The neonate had a minuscule blind orifice in the skin of the sacrococcygeal region, presumably the site of the attachment of the mass. On pathologic examination, it corresponded to an intestinal sac that was interpreted as part of the parasitic twin or an intestinal duplication [12].

Mecit Kantarcl et al. reported a $2900 \mathrm{~g}$ boy was born by normal vaginal delivery to a healthy young mother. At birth, the infant was found to have a large mass attached to his sacrococcygeal region. Radiologic and histopathological examinations showed long and short bones within the sacral parasite. It was presented as a rare case of parasitic conjoined twin attached to the sacrococcygeal region of the autosite. Surgery was performed when the baby was 1 week old and the mass was excised [13].

Hirayama Y et al. reported a huge sacral mass found

\section{REFERENCES}

1. M. Kara, E. Yılmaz, I. Eminli, E. Töz, İ. Avc, T. Öge, E. Ciğercioğulları. Case report: sacral parasitic twins, Clinical and Experimental Obstetrics \& Gynecology- Vol. XXXVII, no. 3, :240-241, 2010

2. N R Kamal, J Singh, P Dalal, P Sonika, A Rattan. Sacral Rachipagus Parasite: A Case Report. Journal of Neonatal Surgery 2016; 5(2):16)

3. B Dejene, S A. Negash, T N Mammo, A Tadesse, H Getachew, M Derbewe. Heteropagus (parasitic) twins. Pediatric Surgery Unit, Department of Surgery, Addis Ababa University, Ethiopia, Journal of Pediatric Surgery at 30 weeks of gestation by fetal ultrasonography. The fetus was delivered by a cesarean operation at 37 weeks and 6 days of gestation. The alphafetoprotein (AFP) level was $174,640 \mathrm{ng} / \mathrm{ml}$. The mass separated by an operation one the day after her birth contained structures similar to imperfect limbs and backbone. A variety of tissue and organs having derived from three germ layers were identified within the mass and showed a tendency to be highly differentiated. Even though a large proportion of the central nervous system tissue showed immature and dysplastic features, no evidence suggested the presence of neoplasm. The infant has shown normal growth and did well without a recurrence of the sacral mass or any elevation in the serum AFP level during the 12-month follow-up. The case was considered as a sacral parasite rather than a sacrococcygeal teratoma [14].

In the majority of parasitic twin cases reported, the anterior upper abdominal and chest parts remain the most common location of the parasite. In sacral parasitic (Rachipagus) twin being rare, antenatal ultrasound should have a high index of parasitic twin suspicion and postnatal sacral mass clinically should include parasitic twins as a differential.

\section{CONCLUSION}

Our case is an atypical and rare form of parasitic twin. This is explained by the fact that it had two axes on the distal part of the back of the autositic twin, which is the site of the initiation of the gastrulation. This suggests a hypothesis of the duplication of the primitive streak after it has been initiated. In general, parasitic twins tend to be acranial (without a skull).

Case Reports 37 (2018) 44-49)

4. N Khavanin, J R Ruge, FA Vicari, E J Belin, R G Kellogg, J P. Steinberg. Parasitic rachipagus conjoined twin: case report.

J Neurosurg Pediatr 22:313-316, 2018

5. What Is a Parasitic Twin? Accessed: Dec. 27, 2020. [Online]. Available

https://www.healthline.com/health/pregnancy/ parasitic-twin\#in-the-news

6. Alastair J.W. Millar. Conjoined and parasitic twins. In Pediatric Surgery: A Comprehensive Textbook for Africa. Edited by Emmanuel A. Ameh, Stephen W. Bickler, Kokila Lakhoo, Benedict C. Nwomeh, Dan 
Poenaru, 2nd edition, Switzerland, 2020, Ch. 124, page 750-755

http://doi.org/10.1007/978-3-030-41724-6

$7 . \quad J$. Hitayezu, J. Gashegu, J. Vyankandondera, L. Mutesa. An Unsual Case of Conjoined Twins. Rwanda Medical Journal, Sept. 2010, Vol. 68 (3)

8. Catharine Paddock. Embryonic parasitic twin removed from 9-year-old girl's Stomach. Greece, 2008, http://www.medicalnewstoday.com/articles/107814. php, Accessed 25 May 2011.

9. Kaufman $\mathrm{MH}$. The embryology of conjoined twins. Edinburgh, UK.

University of Edinburgh, Hugh Robson Building, George Square, EH8 9XD.

Childs Nerv Syst.2004 Aug;20(8-9):508-25. Epub 2004 Jul 27.

10. G Sharma, SS Nazarian Mobin, M Lypka, M Urata. Heteropagus (parasitic) twins: a review.

J Pediatr Surg. 2010 Dec;45(12):2454-63. doi: 10.1016/j. jpedsurg.2010.07.002.

11. SY Chou, SJ Liang, CF Wu , Hsu . Sacral parasite conjoined twin. Taiwan

Obstet Gynecol. 2001 Nov; 98(5 Pt 2): 938-40

12. Maria Okumura, MD. Unusual Presentation of a Sacral Parasitic Conjoined Twin. Brazil, University of São Paulo, São Paulo

J Ultrasound Med, 2011,30:281-283 • 0278-4297

13. Mecit Kantarcı et al. Sacral Parasite Conjoined Twin Mimicking Sacrococcygeal Teratoma: MultiDetector CT Findings. Turkey

Department of Radiology Faculty of Medicine, Atatürk University, Erzurum, 2010, Cilt 32, Sayı 1, Sayfa (lar) 065068

14. Y Hirayama, M Kubota, A K akita et al. Sacral parasite with histopathological features of an unequally conjoined twin. Pediatr Surg Int 23, 715-720 (2007). https://doi.org/10.1007/s00383-007-1880-3 